www.jmscr.igmpublication.org

Impact Factor 5.244

Index Copernicus Value: 5.88

ISSN (e)-2347-176x ISSN (p) 2455-0450

crossref DOI:_http://dx.doi.org/10.18535/jmscr/v4i3.16

Journal Of Medical Science And Clinical Research

IGM Publication

An Official Publication of IGM Publication

\title{
Antibiotics Susceptibility Profile of E.Coli in Female Students of University of Agriculture Makurdi
}

\author{
Authors \\ Yaji, M.E' ${ }^{1}$ Gberikon, G.M. ${ }^{2}$, Okpe.L ${ }^{3}$. \\ Department Of Biological Sciences, \\ Federal University of Agriculture, Makurdi, Benue State Nigeria. \\ Corresponding Authors \\ Yaji, M.E \\ Email: yajimnena@gmail.com
}

\begin{abstract}
A study to determine antibiotic susceptibility profile of E.coli urinary tract infection among female students of University of Agriculture, Makurdi was under-taken. A total of 100 early mornings, mid -stream urine samples were collected and cultured on Cystein Lactose Electrolyte Deficiency (CLED) and Eosine Methylene Blue (EMB). Out of the 100 samples, 48 had growth. E.coli was 25\%, Staphylococcus aureus 9\%, Candida albicans 8\%, Klebsiellaspp 4\%, Pseudomonas and Proteus spp 2.1\%. E.coli had the highest percentage while proteus and Pseudomonas had the lowest. However it was not statistically significant. Antibiotic susceptibility test by disc diffusion method indicated that, the most effective antibiotics was gentamycin with 92\%, while the most resistant was septrin with 16\%. Others were Ciprofloxacin $76 \%$, ofloxcin 60\%, sperfloxacin 24\%, amoxicillin $24 \%$, and chloramphenicol 16\%. E.coli is a common etiologic agent of urinary tract infection (UTI) among female students in University of Agriculture, Makurdi and its antibiotics susceptibility profile indicates that UTI caused by E.coli can be effectively treated.
\end{abstract}

\section{INTRODUCTION}

Urinary tract infection (UTI) is the infection of any part of the urinary tract. The urinary tract consists of the kidneys, ureter, bladder and urethra. Any part of these structures can become infected, but bladder and urethra infection are the most common. The infection of the bladder is known as cystitis while that of the urethra is known as urethritis (Anon, 2006). There are two types of UTI, the lower and upper urinary tract infections. The lower type affects the bladder and the urethra while the upper part affects the kidney and the ureter. The upper UTI is of more serious complication because it has the possibility of damaging the kidney (Ani, 2008).

Urinary tract infections are caused by the presence of bacteria most frequently Escherichia coli in urine, although, fungi and viruses could be involved with majority of women having recurrent infection within a year. The bacteria that cause UTI enters the bladder through the urethra and is transmitted from the urethra to the bowel, however, infection also occur through the blood and the lymph. Poor toilet habit, pregnancy in women and prostate enlargement in male can predispose one to infection. (Siiriet al., 2009, Salvatore et al., 2001). 
According to Asda (2006), increasing resistance in bacteria pathogens is of world Wide concern. The prevalence of antimicrobial resistance in both out and in patients with UTI is increasing and can vary according to geographical and regional location. In UTI, antimicrobial therapy is initiated even before the results of urine culture are available due to uncontrolled use of antibiotics. Hence, there exist a great need for antimicrobial susceptibility profile surveillance at local, national and international level.

The ratio of UTI in male and female varies according to Macnair (2006), about $11 \%$ of girls and $4 \%$ of boys have UTI before they reach the age of 16 , while about $40-50 \%$ of women and $12 \%$ of men have UTI at sometimes of their lives. This difference may be attributed to some factors such as sexual activity which may be responsible for high infection rate in sexually active women as the problem begins when a woman becomes sexually active. Infection also increase in people living with diabetes. Women are often prone to UTI than men, this is attributed to their short and wide urethra, the anatomical relationship between the urethra and vagina makes it liable to trauma during sexual intercourse as well as bacteria messaged up the urethra into the bladder during pregnancy. Women are more prone to UTI than men because their urethra is shorter and closer to the anus than in men. Hence bacteria from the anus can pass easily into the urinary tract. Women also have three openings in a very small area (the rectum, the vagina and the urethra meatus).

Women also lack the bacteriostatic properties of prostatic secretions that are present in men, they are also susceptible to recurrent UTIs because they do not secrete certain blood group antigens (Mercola, 2001, Duerdenet al., 1990, Thompson, 2006).

Etiological and clinical presentation of UTI is similar in both developed and developing nations, but the range of infection varies from place to place (Latif, 2004). The control of microorganism is critical for the prevention and treatment of UTIs so as to prevent suffering that might occur as a result of the effect of the pathogens present in the human system and environment.

Urinary tract infections are treated with the use of broad spectrum cephalosporins, Flouroquinolones and Aminoglycosides (Trevor et al., 2001). For effective management of UTI, antibiotic susceptibility testing (AST) is usually carried out to determine which antibiotic will be most successful in treating bacterial infections in vivo. Testing for antibiotic sensitivity is often done by the Kirby-Bauer method, stroke method, agar and broth dilution methods. The Kirby-Bauer disc diffusion method is the most commonly and currently used technique in clinical microbiology laboratories. It was developed in early 1960s by William Kirby and A.W. Bauer. Kirby-Bauer test results do not give actual MIC (Minimum Inhibitory Concentration) values, but are interpreted as susceptible, intermediate or resistant based on comparison of zone of inhibition to a standard table.

According to Clinical and Laboratory Standard Institute (CLSI) (1999), susceptibility implies that "isolates are inhibited by the usually therapeutic tissue concentration when the right dosage of the agent is used for the site of infection. The resistant category implies that "isolate are not inhibited by the usually therapeutic tissue concentration of agent with normal dosage schedules, and/or that show zone of inhibition that fall within the range where specific microbial resistance mechanisms (e.gbet-lactamase) are likely and intermediates include "Isolates with MIC, that is close to usually therapeutic tissue concentration and for which response rates may be lower than that of susceptible isolates.

While the Agar and Broth dilution methods, are used to determine Minimum Inhibitory Concentration (MIC) and Minimal lethal Concentration (MLC). (Willey et al, 2008).

UTI is a serious health problem affecting millions of people each year. It is the second most common type of infection in the body, accounting for 8.3 million visit to hospital each year (UDHHS, 2004). Urinary tract infection is caused by the presence of bacteria in urine with E. Coli 
accounting for $75.90 \%$ while micrococci infection may also account for up to $10-30 \%$ of cases in sexually active women (Voland et al.,2001). Resistance to antimicrobial agents has increased remarkably since the introduction of UTI treatment. Many World Wide reports show a noticeable increase in Ciprofloxacine and other fluoroquinolone resistance (Dimitriv; 2004).

Concurrent resistance to antimicrobials of different structural classes has arisen in a multitude of bacterial species, including isolates of E. Coli, the most prevalent pathogen contributing to these infections and may complicate the therapeutic management of infections, including those of urinary tract. This has necessitated this study

\section{Objective of The Study}

The objectives of this study include;

1. To isolate E. coli from urine of female student attending university of Agriculture Health Center Makurdi.

2. To determine the antibiotic susceptibility profile of the E. coli isolates.

\section{Sample Collection}

A total of 100 early morning mid-stream urine samples were collected from female students in block A and B hostels of federal university of agriculture Makurdi . The students were given labelled sterile sample bottles and instructed to produce early morning mid-stream urine directly inside the sample bottle given to them. The samples were then collected from them and transported to the laboratory in a cooler box within two hours.

\section{Laboratory Culture}

A wire loop was sterilized by placing it on a blue flame at $45^{\circ} \mathrm{C}$ until red hot, it was allowed to cool and placed inside the sample bottle containing the urine after gentle mixing, a loop full of the urine was taken and streaked on cystein lactose electrolyte deficiency media (CLED). It was incubated at $37^{\circ} \mathrm{C}$ for 24 hours, the colonial morphology was observed after the incubation period and the colonies that appeared yellow were picked and sub cultured on Eosine methylene blue agar (EMB), it was again incubated at $37^{\circ} \mathrm{C}$ for another 24 hours after which the colonial morphology were observed and recorded.

\section{Gram Staining And Microscopy}

A labelled clean glass slide was placed on a flat work bench and a drop of normal saline was put on it. The colonies that appeared as green metallic sheen on the EMB were picked with the aid of a sterile wire loop and emulsified on the normal saline and spread out to make a thin layer. The smear was allowed to air dry and heat fixed by passing it over a bunsen burner flame three times with the smear surface facing up. The slides were then placed on a clean rack and flooded with crystal violet (primary dye) and allowed to stand for 60 seconds, the slides were rinsed with water and Grams iodine a mordant was poured on the slides and allowed to stand for another 60 seconds, and rinse with water the slides were then flooded with acetone and washed off immediately, they were flooded with safranin for counter staining and allowed to stand for 60 seconds after which they were washed, back cleaned, and allowed to dry in slanting position at room temperature.

A drop of oil immersion was placed on each dried stained slides and viewed under the microscope with x100 objective, the Gram reaction and morphology of the organism were observed and recorded (Cheese brough, 2000).

\section{Characterization}

The organism that appeared to be pink as observed under the microscope were subjected to biochemical test to further identify the isolated organism as follows

\section{Indole Test}

The organism were grown in $5 \mathrm{mls}$ of peptone water in a test tube for 24 hours at $37^{\circ} \mathrm{C}$, three drops of kovaks reagent was added to the turbid peptone water. A positive result was indicated by the development of a red colour in the reagent 
portion above the broth within a minute, in a negative reaction, the indole reagent retained its yellow colour (Cheesebrough, 2000).

\section{Citrate Test}

The isolates were inoculated on citrate slant in a test tube, it was incubated at $37^{\circ} \mathrm{C}$ for 24 hours. The development of a deep blue colour indicates a positive reaction and no clour change indicates a negative reaction (Cheesebrough, 2000)

\section{Methyl Red-VogesProskauer Test}

The isolated organisms were inoculated in $10 \mathrm{mls}$ MRVP broth and incubated for 48 hours at $37^{\circ} \mathrm{C}$, $5 \mathrm{mls}$ of the broth was transferred into a test tube, 5 drops of methyl red indicator was added and mixed properly, a positive reaction was indicated by the development of an intense red colour. To the other $5 \mathrm{mls}$ of a MRVP broth, 5 drops of $4 \%$ potassium hydroxide $(\mathrm{KOH})$ and 5 drops of $5 \%$ anapthnol reagent was added, the tube was shaked and placed in a sloping position. The presence of a red colour indicates a positive result absence indicates a negative result.

\section{Susceptibility Testing}

Antibiotic susceptibility test was carried out on isolates of E.coli using the Gram negative multiple antibiotic disc containing the following antibiotics: Septrin, Gentamycin, Ofloxacin, Streptomycin, Amoxacin, Chloramphenicol, Sparfloxacin and Ciprofloxacin.

Sterile distilled water was poured in a sterile universal bottles and the isolated organism was picked and put into the bottles using a sterile wire loop, this was done until the organism in the bottle was of the same turbidity with 0.5 McFarland standard (Cheesebrough, 2000).

$0.5 \mathrm{mls}$ of the standardized organism was pipetted and placed on a freshly prepared Mueller Hinton Agar and with the aid of a sterile swab stick it was evenly spread over the surface of the agar and allowed for an hour to diffuse, the antibiotic disc was picked with a sterile forcep and asseptically placed on the Mueller Hinton agar, the plates were incubated at $37^{\circ} \mathrm{C}$ for 24 hours after which the plates were observed for the zones of inhibition which appeared as clear areas around the disc completely devoid of bacteria growth, all observed zones were measured using a transparent rule and interpreted using the National Committee For Clinical Laboratory Standard(NACCLS ) (Cheesebrough, 2000).

Based on these measurements, strains susceptible and resistant to each antibiotic were deduced and the percentage calculated as follows:

Percentage susceptibility of E.coli to each antibiotic is $=$

No of susceptible isolates

X 100

Total isolate

And

Percentage resistance of E.coli to each antibiotic is $=$

No of resistant isolates

X 100

Total isolates

\section{RESULTS}

According to the results obtained, E. coli is the predominant cause of urinary tract infection among female students in Federal University of Agriculture, Makurdi.

Out of the 100 samples tested 48samples had growth while 52 samples had no growth.

Table 1: Shows the prevalence of microorganisms isolated from female students. Out of the 48 isolates, $E$ coli with 25(52\%) was the most prevalent while Pseudomonas spp and Proteus spp were the least prevalent with 1(2.1\%) each.

Tale 2: Shows the prevalence of E.coli infection in female students based on age. Escherichia coli urinary tract infection was more common among female students in the age group of $21-25$ years, and least less within the 16-20 age group.

Table 3: Shows the susceptibility of E coli isolate from female students to different antibiotics. The antimicrobial susceptibility profile of the bacteria isolates from urine samples showed that the susceptibility of almost all the bacteria isolates to chloramphenicol, sperofloxacin, amoxicillin, and 


\section{JMSCR Vol||04||Issue||03||Page 9684-9692||March}

septrin was less than $25 \%$ (range16-24\%). The most active drugs against the isolates were gentamycin, streptomycin, ofloxacin and ciprofloxacin (52-92\%), Non was however active against all the bacteria isolates tested. From the result the most effective antibiotic was
Gentamycin with $92 \%$. and the least effective was Septrin with $16 \%$.

\section{Statistical Analysis}

Statistical analysis performed was the Chi-square test and $\mathrm{p}$ - values of $\leq 0.01$ were considered significant.

Table 1: Prevalence of microorganisms isolated from female students

\begin{tabular}{llc}
\hline S/no & Bacteria isolate & Number infected $(\%)$ \\
\hline & & \\
1. & Escherichia coli & $25(52.0)$ \\
2. & Staphylococasaureus & $9(18.8)$ \\
3. & Candida albicans & $8(16.7)$ \\
4. & Klebsicliaspp & $4(8.3)$ \\
5. & Pseudomonas spp & $1(2.1)$ \\
6. & Proteus spp & $1(2.1)$ \\
& & \\
Total & $48(100)$ \\
$\chi^{2}=0.67, \mathrm{df}=5, \mathrm{p}$-value $=0.95$ & \\
\hline
\end{tabular}

Table 2: prevalence of E.coli infection in female students based on ag

\begin{tabular}{lccc}
\hline Age (years) & No of students & No infected $(\%)$ & Not infected\% \\
\hline $15-20$ & 20 & $2(8)$ & $18(24)$ \\
$21-25$ & 40 & $12(48)$ & $28(37.3)$ \\
$26-30$ & 36 & $10(40)$ & $26(34.7)$ \\
$30-35$ & 4 & $1(4)$ & $3(4)$ \\
Total & 100 & $25(100)$ & $75(100)$
\end{tabular}

$\chi^{2}=0.00, \mathrm{df}=3, \mathrm{p}$ - value $=1.00$

Table 3.Susceptibility of E.coli to different Antibiotics.

\begin{tabular}{llcc}
\hline S/no & Antibiotis & No Susceptible $(\%)$ & No Resistant No $(\%)$ \\
\hline 1. & Septrin & $4(16)$ & $19(76)$ \\
2. & Chloramphenicle & $4(16)$ & $16(64)$ \\
3. & Sparfloxacine & $6(24)$ & $15(60)$ \\
4. & Amoxacillin & $6(24)$ & $10(40)$ \\
5. & Ciprofloxacine & $13(52)$ & $2(8)$ \\
6. & Ofloxcine & $15(60)$ & $10(40)$ \\
7. & Streptomycine & $19(76)$ & $8(24)$ \\
8. & Gentimycin & $23(92)$ & $2(8)$ \\
\hline
\end{tabular}

$\chi^{2}=0.00, \mathrm{df}=7, \mathrm{p}$-value 0.96 


\section{DISCUSSION}

The prevalence of UTI in the population was $48 \%$. This figure is higher than prevalence rate of $25.6 \%$ significant bacteriuria recorded by Nedolisa (1998) at the Jos University Teaching Hosoital (JUTH), Nigeria and $38.6 \%$ rate recorded by Akinyemiet al. (1997) in Lagos, Nigeria. The high prevalence may be due to different factors like sexual intercourse, peer group influence, low social- economic status, common among Nigeria females and males (Andriole, 1985, Akinyemiet al., 1997). Poor hygiene and poor sanitary condition of the girls hostel may be responsible for high prevalence among the students.

The result showed that $E$.coli was the predominant cause of UTI among female students in University of Agriculture, Makurdi (UAM). However, it was not statistically significant (Table 1). Out of the 48 isolates obtained, gram negative bacteria had a higher frequency of occurrence than gram positive constituting $31(64.6 \%)$ of the total isolates. These include: E.coli, Klebseillaspp, Pseudomonas spp, and Proteus spp. Gram positive accounted for $9(18.8 \%)$, while the fungus Candida albicans was $8(16.7 \%)$. This finding is similar to other reports which indicate that gram negative bacteria, particularly E.coli, is the commonest pathogen isolated in patients with UTI (Njokuet al., 2001, Mbuta, 2007).

The results also indicated a high percentage of the organism from female students within the age brackets of 21-25 years, 26-30years and 31-35. This also was not statistically significant (Table 2). This may be attributed to the fact that people in these age brackets are more sexually active (Macnair, 2006).

In the antimicrobial susceptibility profile of the isolates, there were variations in their activities, but statistically no significant difference was found in the susceptibility of E.coli to the various antibiotics (p-value $>0.01$ ). Among the antibiotics, gentamycin showed good activity with 92\% isolates found susceptible, which is more than what was recorded in Israel (29\%) (Tank et al., 2004). This may be due to increased use of gentamycin in Israel as compared to UAM,
Nigeria. This was followed by streptomycin with $76 \%$.

The observed susceptibility of E.coli to ciprofloxacin and ofloxacin in this study is relatively high, which are 52\% and $60 \%$ respectively . However, the susceptibility to Ciprofloxacin observed was low compared to 93.75\% recorded by Ehinmidu (2003), which may be attributed to excessive abuse and nonadherence to Cipropfloxacin, allowing E. coli to develop resistance against the agent.

Susceptibility of E.coli to chloramphenicol, sperfloxacin, and amoxicillin was $16 \%, 24 \%$, and $24 \%$ respectively; the readily availability and low price of this drugs may have allowed their frequent and indiscriminate use, consequentially permiting emergent of resistant E.coli strain to these agents. Based on this findings, these antibiotics cannot be used as empirical therapy for the treatment of UTI among the study population.

Studies from USA, Europe and most other countries have shown better susceptibility pattern for pathogens isolated from UTI against Septrin (Mazzuliet al ., 2001, Bonsu et al., 2006). But in this region of the world Septrin has shown poor activity by this study. The reason for this may be due to extensive use by the students. Among the $25 \%$ E. coli, $19(76 \%)$ strains were resistant to septrin. Hence septrincan not be recommended as an empirical therapy for the treatment of E.coli UTI among the female students.

However, it is important to note that, this findings may not be a true representation in every locality (Latif, 2004).

\section{CONCLUSION}

The study showed that E.coli is one of the common etiological agents responsible for urinary tract infection among female students in Federal University of Agriculture, Makurdi. Despite the increasing resistance of the organism to some antibiotics, it is still susceptible to other antimicrobials such as gentamycin, streptomycin, ofloxacin and ciprofloxacin .

Recommendations 
The results of this study revealed that the infecting organisms were mostly commensals of perianal and virginal origins. This calls for increase in personal hygiene among the female students.

Irrational use of drugs to treat urinary tract infection should be strongly discouraged; by proper health education of students and establishment of correct prescription guidelines and regulation for appropriate usage of antibiotics. In the same vein, awareness should be created on the early signs and complication of the infection. Based on this finding, we suggest the need for constant monitoring of susceptibility of specific pathogens in different populations to commonly used anti-microbial agents. These data may be used to determine trends in antimicrobial susceptibility, to formulate local antibiotics policies, to compare local with national data and above all to assist clinicians in the rational choice of antibiotics therapy to prevent misuse, or overuse of antibiotics.

We also suggest that further molecular studies should be carried out to identify which strains are resistant or susceptible to the commonly used antibiotics.

\section{REFERENCES}

1. Akinjogunla, O. J, Odeyemi, A. T, and Olasehinde, G. I (2010). Epidemiological Studies of Urinary Tract Infection (UTI) among Post-menopausal Women in Uyo Metropolis, South-South, Nigeria. Journal of American Science; 6(12).

2. Amdekar, S; Singh, V, Singh, DD (2011). "Probiotic therapy: immunomodulating approach toward urinary tract infection. ".Current microbiology 63 (5): 484-90.

3. Ani, o. c (2008). Prevalence of urinary tract infections (UTI) in sexually active women of Abakaliki, Ebonyi State, Nigeria. Animal Research International . 5(2): $876-879$.

4. ANON (2006).Urinary tract infections in women.http://familydoctor.og/online/famd ocen/home/women/genhealth/190/html
5. Asad U Khan and Mohd S Zaman (2012). Multiple drug resistance pattern in Urinary Tract Infection patients in Aligarh biomedical research; 17 (3): 179-181.

6. Calderon CB, Sabundayo BP (2007). Antimicrobial Classifications: Drugs for Bugs. In Schwalbe R, Steele-Moore L, Goodwin AC. Antimicrobial Susceptibility Testing Protocols.CRC Press.Taylor \& Francesgroup.ISBN978-0-8247-4100-623.

7. Cheesbrough M (2000). District Laboratory Practice in TropicalCountries. $5^{\text {th }}$ Edition, Cambridge United Press, U.K.27 pp.

8. Dienye, P.O., Gbeneol, P.K (2011). Contraception as a Risk Factor for Urinary Tract Infection in Port Harcourt, Nigeria: A Case Control Study. African Journal Of Primary Health Care Family Medicine; 12(4): 220-230.

9. Dimitriv TS, udo EE, Emara M, Awni F, Passadilla R (2004). Etiology and antibiotic in central, Madagascar :Uropian Journal Of Rural Community Health Care. 13(7): 80-88.

10. Dorlands Medical Dictionary: antibacterial". Archived from the original on 2010-11-17.Retrieved 2010-10-29.

11. Dorlands Medical Dictionary:antibiotic". Archived from the original on 2010-1117.Retrieved 2010-10-29.

12. Duerden B .I, Reid TMS, Jewsbury J . M, Turk DC (1990). UTI risk factors .A New Shortbook of Medical Parasite. $7^{\text {th }}$ edition, Baltmore:Lippicott Williams and Wilkins. $175 \mathrm{pp}$.

13. Feng P, Weagant S, Grant, M (2002-0901). "Enumeration of Escherichia coli and the Coliform Bacteria". Bacteriological Analytical Manual (8th ed.). FDA/Center for Food Safety \& Applied Nutrition. Retrieved 2007-01-25.

14. Gruneberg RN (1994). Changes in urinary pathogens and their antibiotic sensitivities.J AntimicrobChem-other ; 33: $1-8$. 
15. Jombo , G.T, Egah , D.Z , Banwat , E.B , Ayeni, J.A (2006). Nosocomial and Community Jombo acquired Urinary Tract Infections at a Teaching Hospital in North Central Nigeria: findings from a study of 12,458 urine samples. Nigerian Journal of Medicine, 15(3):230-6

16. KarlowskyJ .A, Jones M.E, Thornsberry C, Critchley, I, Kelly L, Sahm D (2001). Prevalence of antimicrobial resistance among pathogens isolated from female outpatients across the US in .Int $J$ AntimicrobAgents ; 18: 121-127.

17. LATIF, A. S (2004).Urogental infections in the tropics.Pages. In: LATIF, A. S and SPINGS, A. (Eds). STI/HIV project.The Australasian College of Tropical Medicine Publishing Press, Harare. 60pp.

18. MACNAIR, I (2006). Urinary Tract infection

http://www.bbc.co.uk/health/conditions/uri narytract 2. shtml

19. Mathai D, Jones R.N, Pfaller M .A (2001) Epidemiology and frequency of resistance among pathogens causing urinary tract infection in 1,510 hospitalized patients: a report from the SENTY Antimicrobial Surveillance Program (North America) DiagMicrobiol Infect Dis; 40: 129-136.

20. MERCOLA, J (2001). Cranberry juice for urinary tract infections.Bitish Medical Journal, 322: 1571 -

21. National Committee for Clinical Laboratory Standards (NCCLS)( 2000). Methods for dilution isolate for antimicrobial susceptibility tests for bacteria that grow aerobically: Approved standard - 5th edn. NCCLS document M7A5 (ISBN 1-56238-394-9) NCCLS. Wayne, Pennsylvania 19087-1898, USA.

22. National Committee for Clinical Laboratory Standards (1999).Performance standards for antimicrobial susceptibility testing.Ninth informational supplement. 18, number 1. Wayne, Pa: National
Committee for Clinical Laboratory Standards.

23. Obiogbolu, C. H, Okonko, I. O, Anyamere, C. O, Adedeji, A. O, Akanb,i A. O, Ogun, A. A, Ejembi, J. and Faleye, T. O. C (2009).Incidence of Urinary Tract Infections (UTIs) among pregnant women in Akwa metropolis, Southeastern Nigeria. Scientific Research and Essay . 4 (8).8

24. Willey, L .S, Chris Woolverton (2013) . Antimicrobial Chemotherapy. Microbiology , 13th Edition,McGraw-Hill Book. Htt://create.mcgraw-hill.com. 195pp.

25. Willey, L .S, Chris Woolverton (2013) . Development of Antibiotic Resistance in Bacteria .Microbiology, 13th Edition, McGraw-Hill Book. Htt://create.mcgrawhill.com. 398pp.

26. SA Waksman (1947). "What Is an Antibiotic or an Antibiotic Substance?".Mycologia 39 (5): 565-569.

27. Salvatore, S, Salvatore, S, Cattoni, E, Siesto, G, Serati, M, Sorice, P, Torella, M (2011). "Urinary tract infections in women.". European journal of obstetrics, gynecology, and reproductive biology 156 (2): 131-6.

28. Stamm W.E, Hooton T.M (1993) .The management of urinary tract intections. $N$ Engl J Med ; 329: 1328-1334.

29. Thompson, Andrea (2007). "E. coli Thrives in Beach Sands". Live Science. Retrieved .06/04/2007.

30. THOMPSON, T (2006). Urinary Tract Infection Medication: Antibiotics for UTI. http://www.nativeemedies.com/articles/uri nary-tract-infection-medicationantibioticsuti. html.9

31. Todar, K (2007) ."Pathogenic E. coli".Online Textbook of Bacteriology. University of Wisconsin-Madison Department of Bacteriology. Retrieved Infection. ELBS Publishers.576-582.

32. Todar, K. (2010). Pathogenic E. coliInTodar's Online Textbook of 
Bacteriology. Retrieved from

http://www.textbookofbacteriology.net/e.c

oli_4.html

33. Von Nussbaum F (2006). "Medicinal Chemistry of Antibacterial Natural

Products - Exodus or Revival?".Angew.

Chem. Int. Ed. 45 (31): 5072-5129.

34. Warren J.W, Abrutyn E, Hebel J.R, Johnson J.R, Schaeffer A.J, Stamm W.E (2007).Guidelines for antimicrobial treatment of uncomplicated acute bacterial cystis and acute pyeloephritis in women. Clin Infect Dis 199; 29: 745-758.

35. Willey, L.S Chris Woolverton (2013) . Antimicrobial Chemotherapy. Microbiology, 13th Edition,McGraw-Hill Book. Htt://create.mcgraw-hill.com. 189pp

36. Witte W (2004). "International dissemination of antibiotic resistant strains of bacterial pathogens".Infect. Genet.Evol. 4 (3): 187-91. 